\title{
Reconceptualised Family Resemblance Approach to Nature of Science in Pre-Service Science Teacher Education
}

\author{
Ebru Kaya, Bogazici University, Turkey \\ Sibel Erduran, University of Oxford, UK \\ Busra Aksoz, Bogazici University, Turkey \\ Selin Akgun, Bogazici University, Turkey
}

\begin{abstract}
Nature of Science (NOS) has garnered a significant amount research in science education. A recent framework on NOS is the so-called "Family Resemblance Approach" (FRA) which presents NOS as a cognitive-epistemic and social-institutional system with a set of categories: aims and values, scientific methods, scientific practices, scientific knowledge and socialinstitutional aspects of science. Although FRA has been problematised philosophically and its implications for science education have been considered by science educators, its empirical adaptations in science education are limited. We present a study based on a funded preservice science teacher education project whose aim was to design, implement and evaluate the impact of a series of sessions using FRA-informed NOS strategies. In order to differentiate the educational adaptations of FRA, we refer to Reconceptualised Family Resemblance Approach to Nature of Science or RFN. A total of 15 female participants from a four-year undergraduate teacher education programme attended in a series of 14-week sessions. A 70-item questionnaire entitled "RFN Questionnaire" was designed to investigate the outcomes of the teacher education intervention relative to the learning goals set for each session that focused on a particular RFN category. Individual interviews with PSTs were also conducted. Quantitative and qualitative data analysis of RFN categories results suggest that the teacher education intervention had an overall significant impact on pre-service teachers' views of NOS. The paper contributes to understanding of how NOS can be incorporated in science teacher education using a new orientation to NOS based on FRA.
\end{abstract}

Keywords: Nature of science, pre-service teacher education, family resemblance approach 


\section{Introduction}

Nature of science (NOS) has been a curriculum goal for several decades (e.g. Conant, 1961; Kimbal, 1968; Rubba \& Anderson, 1978;). A contemporary account of NOS in the science education research literature (e.g. Lederman, Abd-El-Khalick, Bell, \& Schwartz, 2002; McComas \& Olson, 1998) referred to as a "consensus view" of NOS has been applied to curriculum analysis (e.g. McComas, 2014; 1998), assessment (e.g. Lederman, Abd-ElKhalick, Bell \& Schwartz, 2002) and teacher education (e.g. Akerson, Cullen, \& Hanson, 2009). For example, using the consensus view of NOS, McComas (2014) reviewed the NOS components of state standards in the USA. Alternative perspectives on NOS have recently emerged, and have included the idea of "Whole Science" (Allchin, 2011), "Features of Science" (Matthews, 2012) and the "Family Resemblance Approach (FRA)" (Irzik \& Nola, 2014; Erduran \& Dagher, 2014a; Dagher \& Erduran, 2016) although curriculum investigations based on these alternative approaches have been limited (e.g. Erduran \& Dagher, 2014b; Kaya \& Erduran, 2016).

Almost two decades ago, Driver, Leach, Millar, and Scott (1996) highlighted five potential benefits of students' learning of NOS, namely that understanding NOS helps students to (a) understand the process of science, (b) make informed decisions on socio-scientific issues, (c) appreciate science as a pivotal element of contemporary culture, (d) be more aware of the norms of the scientific community, and (e) learn science content with more depth. Although NOS has been a curricular goal for decades, it remains a challenging area for science teachers (e.g. Lederman, Abd-El-Khalick, Bell, \& Schwartz, 2002). While there may be numerous aspects to why the teaching and learning of NOS may be difficult, one critical element is that NOS is a metacognitive approach that is difficult to understand. In other words, NOS is about understanding about how science works, and as such it is about thinking about thinking in science. Furthermore, the concepts surrounding NOS (e.g. tentativeness of scientific knowledge) are not only higher order concepts but they are also typically absent in science teacher education (e.g. Akerson, Cullen \& Hanson, 2009). Although limited in some contexts, science teacher education programmes worldwide have been making efforts to incorporate NOS in teacher education (e.g. Akerson \& Hanuscin, 2007; Bianchini \& Colburn, 2000).

In this paper, we report findings from a funded research and development project that focused on the inclusion of NOS in science teacher education. The project was conducted in a fouryear science teacher education programme at a public university in an urban setting in Turkey. The objectives of the project were to (a) produce a series of workshops in order to incorporate NOS in science teacher education, (b) to improve pre-service science teachers' understanding of NOS through an intervention based on the Family Resemblance Approach (FRA) to NOS. FRA is a recent account of NOS (Erduran \& Dagher, 2014; Irzik \& Nola, 2014). In order to emphasise the distinction of the educational instantiation of FRA (e.g. Kaya \& Erduran, 2016) from its philosophical counterparts (e.g. Irzik \& Nola, 2014), we use the terminology "Reconceptualised Family Resemblance Approach to Nature of Science" or RFN. RFN includes a set of categories including aims and values, methods, practices, knowledge and social context of science embedded in science education practice. The framework will be described in more detail in the rest of the paper. A teacher education 
programme was developed and implemented. Qualitative and quantitative data analyses were conducted to investigate the effectiveness and the quality of the teacher education strategies. Given the scarcity of interventions focusing on teacher education about NOS from an RFN perspective, the study makes an empirical contribution to the limited literature (e.g. Cullinane, 2018).

\section{Nature of Science in Science Education}

Contemporary accounts of NOS in the science education research literature have been reviewed by Chang, Chang, and Tseng (2010) who traced the literature between 1990 and 2007. The key proponents of this area of research in science education (Abd-El-Khalick, 2012; Lederman, Abd-El-Khalick, Bell, \& Schwartz, 2002; Lederman, 1992; McComas, 1998) have outlined a set of statements that characterise what they call a "consensus view" of the nature of science (NOS). The key aspects of this approach are as follows:

“(1) Tentativeness of Scientific Knowledge: Scientific knowledge is both tentative and durable;

(2) Observations and Inferences: Science is based on both observations and inferences. Both observations and inferences are guided by scientists' prior knowledge and perspectives of current science;

(3) Subjectivity and Objectivity in Science: Science aims to be objective and precise, but subjectivity in science is unavoidable;

(4) Creativity and Rationality in Science: Scientific knowledge is created from human imagination and logical reasoning. This creation is based on observations and inferences of the natural world;

(5) Social and Cultural Embeddedness in Science: Science is part of social and cultural traditions. As a human endeavor, science is influenced by the society and culture in which it is practiced;

(6) Scientific Theories and Laws: Both scientific laws and theories are subject to change. Scientific laws describe generalized relationships, observed or perceived, of natural phenomena under certain conditions;

(7) Scientific Methods: There is no single universal step-by-step scientific method that all scientists follow. Scientists investigate research questions with prior knowledge, perseverance, and creativity" (Lederman et al., 2002, pp.500-502).

This consensus view of NOS has led to a major body of empirical studies in science education (e.g. Akerson \& Donnelly, 2008; Abd-El-Khalick, \& Lederman, 2000). While there have been many contributions to research and development on NOS from a consensus view, the discussion on various accounts of NOS in science education is continuing (e.g. 
Allchin, 2011; Erduran \& Dagher, 2014a; Grandy \& Duschl, 2007; Kaya \& Erduran, 2016; Matthews, 2012). There is also a related set of research studies that concern themes implicit in NOS, such as epistemological reasoning (e.g., Sandoval, 2005) and epistemological enactment through inquiry (e.g., Ford, 2008). One recent characterisation of NOS is called the Family Resemblance Approach (FRA). The original approach proposed by philosophers of science Irzik \& Nola $(2014,2011)$ has been considered for science education (Dagher \& Erduran, 2017; Erduran, 2014; Erduran \& Dagher, 2014a, b). Research has been carried out in the applications of the framework in curricular context (Erduran \& Dagher, 2014b; Kaya \& Erduran, 2016), how visual representations can facilitate its teaching (Erduran, 2017) and the implications of the FRA for learning pathways on NOS (Kampourakis, 2016).

In an effort to clarify the elusive definition of the FRA for science education purposes and to distinguish its various senses within philosophy and philosophy of science, Kaya and Erduran (2016) referred to the educational instantiation of FRA as RFN (or Reconceptualised Family Resemblance Approach to Nature of Science) to distinguish the educational adaptations from its philosophical counterparts. Originally, Irzik and Nola (2014) adapted Wittgenstein's generic definition of family resemblance to NOS as Family Resemblance Approach to NOS. In applying Wittgenstein's family resemblance idea to NOS, Irzik and Nola consider the various branches of science as a 'family' with some characteristics that are similar as well as specific to each member. The FRA then can accommodate for both the domain-general and the domain-specific features of science. For example, many science domains rely on data collection and observation. Other practices such as experimentation may be restricted in some domains, such as astronomy. While Irzik and Nola (2014; 2011) adapted Wittgenstein's generic definition of family resemblance idea to NOS, Erduran and Dagher (2014a) expanded and applied Irzik and Nola's definition in science education (Table 1). Erduran and Dagher (2014a) added three categories that they deemed significant for the science curriculum: "social organizations and interactions", "political power structures" and "financial systems". Here, the authors drew attention to the fact that societal and cultural factors impact how science is done. Another aspect of Erduran and Dagher's (2014) work was the introduction of images to summarise and visually communicate some key ideas about NOS (Figure 1). The authors argued that the use of visual images can potentially help inform pedagogical and instructional content about NOS. 


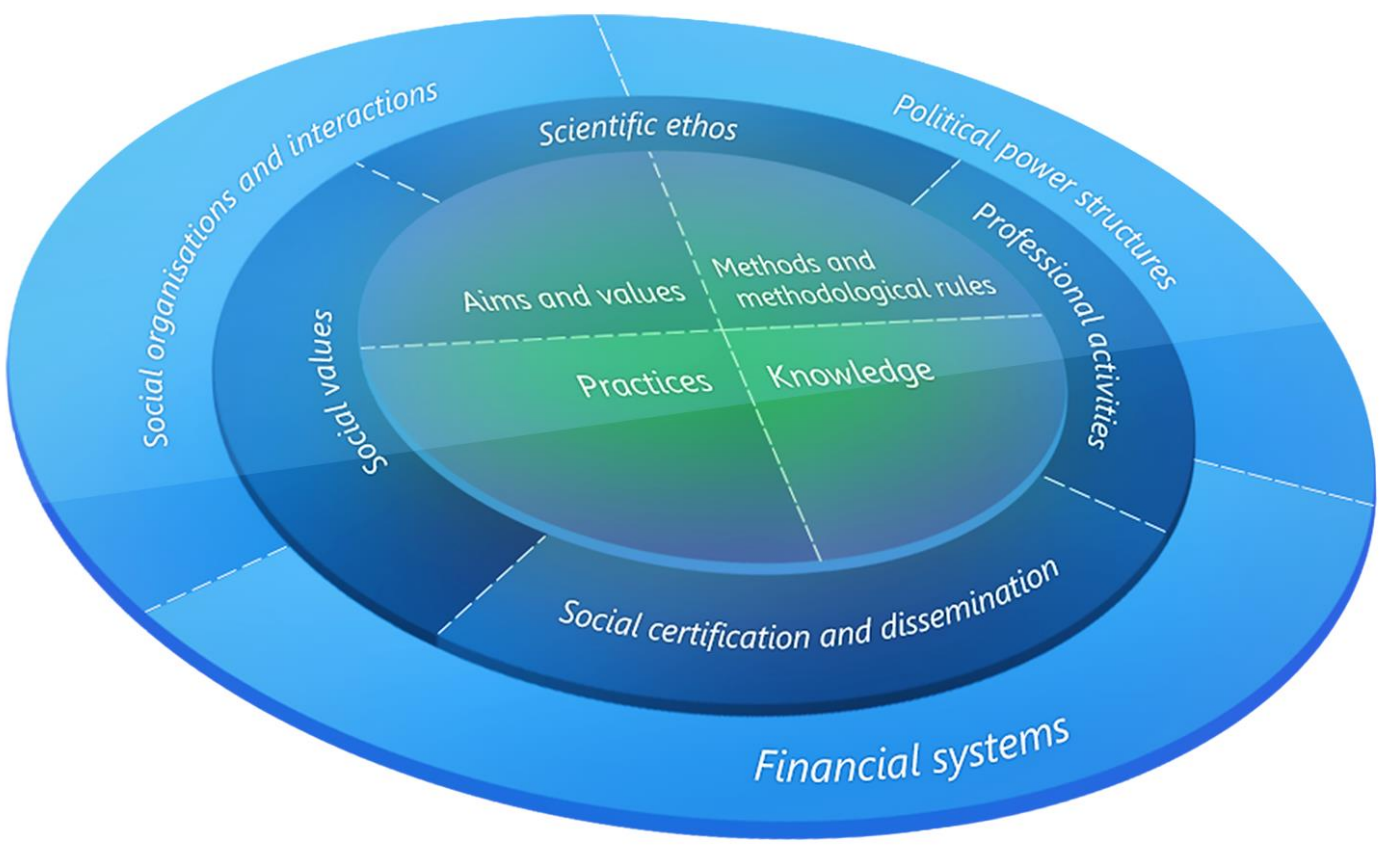

Figure 1. Science as a Cognitive-Epistemic and Social-Institutional System (Erduran \& Dagher, 2014a, p. 28)

Table 1. Definition of Erduran \& Dagher's (2014a) categories.

\begin{tabular}{|l|l|}
\hline Category & Description \\
\hline Aims and values & $\begin{array}{l}\text { Cognitive and epistemic objectives of science, such as accuracy and } \\
\text { objectivity }\end{array}$ \\
\hline Methods & $\begin{array}{l}\text { Manipulative as well as non-manipulative techniques that underpin } \\
\text { scientific investigations }\end{array}$ \\
\hline Practices & $\begin{array}{l}\text { Set of epistemic and cognitive practices that lead to scientific } \\
\text { knowledge through social certification }\end{array}$ \\
\hline Knowledge & $\begin{array}{l}\text { Theories, laws and explanations that underpin the outcomes of the } \\
\text { scientific inquiry }\end{array}$ \\
\hline $\begin{array}{l}\text { Social certification and } \\
\text { dissemination }\end{array}$ & $\begin{array}{l}\text { Social mechanisms through which scientists review, evaluate and } \\
\text { validate scientific knowledge for instance through peer review } \\
\text { systems of journals }\end{array}$ \\
\hline
\end{tabular}




\begin{tabular}{|l|l|}
\hline Scientific ethos & $\begin{array}{l}\text { Norms that scientists employ in their work as well as in interaction } \\
\text { with colleagues }\end{array}$ \\
\hline Social values & $\begin{array}{l}\text { Values such as freedom, respect for the environment, and social } \\
\text { utility }\end{array}$ \\
\hline Professional activities & $\begin{array}{l}\text { How scientists engage in professional settings such as attending } \\
\text { conferences and doing publication reviews }\end{array}$ \\
\hline $\begin{array}{l}\text { Social organisations and } \\
\text { interactions }\end{array}$ & $\begin{array}{l}\text { How science is arranged in institutional settings such as universities } \\
\text { and research institutes }\end{array}$ \\
\hline Financial systems & $\begin{array}{l}\text { Underlying financial dimensions of science including the funding } \\
\text { mechanisms; }\end{array}$ \\
\hline Political power structures & $\begin{array}{l}\text { Dynamics of power that exist between scientists and within science } \\
\text { cultures }\end{array}$ \\
\hline
\end{tabular}

In an effort to illustrate how their account of FRA relates to other characterisations of NOS such as Allchin's "Whole Science" (Allchin, 2011) and Matthew's "Features of Science" (Matthews, 2012), Dagher and Erduran (2017) provided a visual comparison (Figure 2). They used a series of concentric circles whereby each circle attends to the listed components and those of all of the circles it encloses. They highlighted that all approaches emphasise scientific methods and practices but that "Family resemblance approaches subsume all aspects proposed by other colleagues, except for those features of science in Matthews' (2012) account that address philosophical stances such as realism, feminism, and otherisms." (Dagher \& Erduran, 2017, p. 49). 


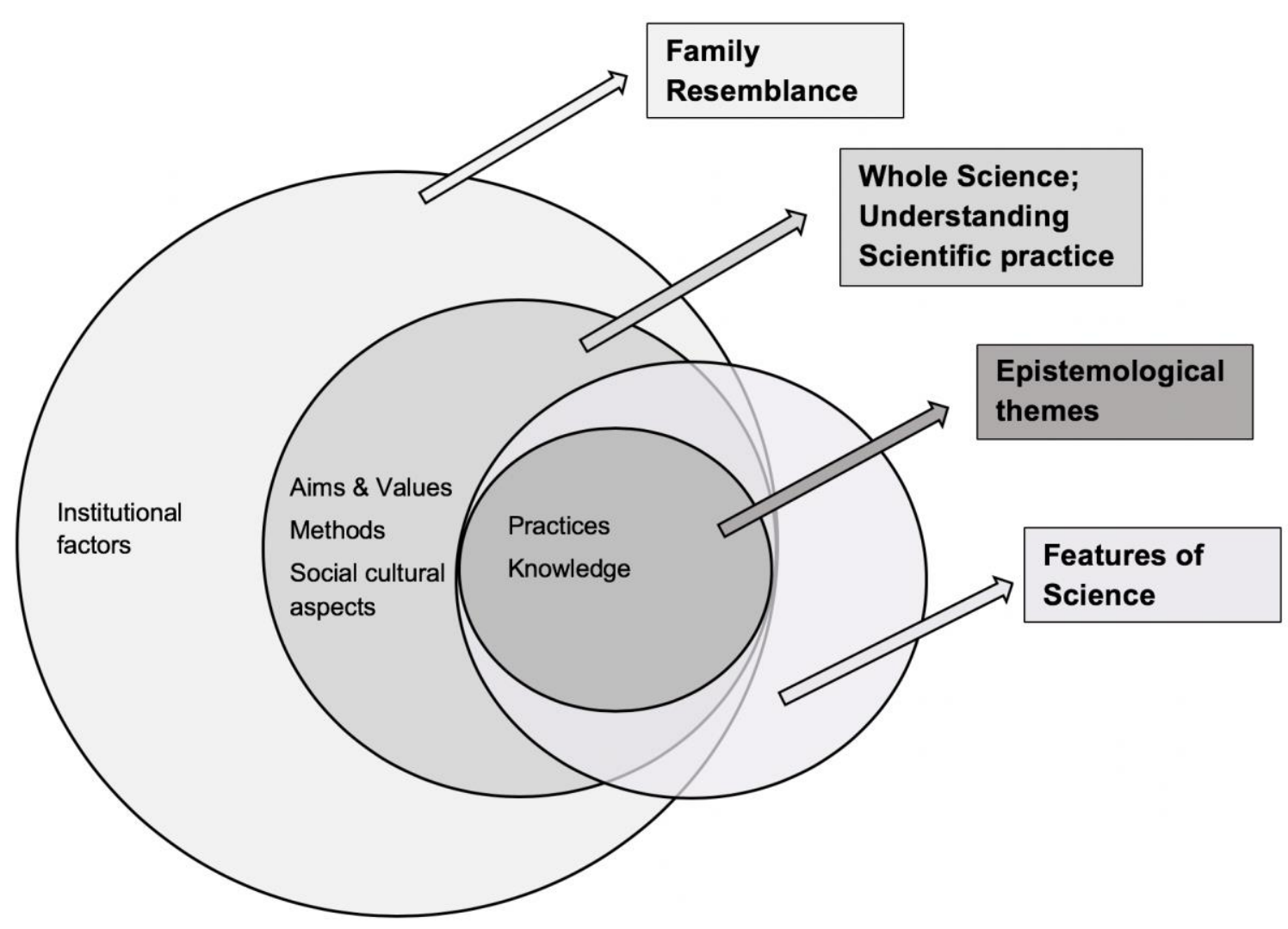

Figure 2. The scope of FRA relative to other alternative views of NOS (adapted from Dagher \& Erduran, 2017, p. 49).

\section{Pre-Service Teachers' Views of Nature of Science}

Pre-service science teachers' (PSTs) views of NOS have been researched extensively (e.g. Akerson, Cullen, \& Hanson, 2009; Akerson, Abd-El-Khalick \& Lederman, 2000; Lederman, Abd-El-Khalick, Bell, \& Schwartz, 2002; Schwartz, Lederman \& Crawford, 2004; Lederman \& Zeidler, 1987; McDonald, 2010; Yacoubian \& BouJaoude, 2010). For example, as significant contributors to the field, Akerson et al. (2000) examined how PSTs interpret the tenets of the consensus view. In their study, pre-service elementary teachers held naive views of many of the investigated aspects of NOS at the beginning of the study. However, further evidence suggested that explicit reflective activity-based approach to NOS instruction undertaken within the context of the investigated science methods course was effective in enhancing pre-service elementary teachers' views. The participants made significant gains in their understandings of the target aspects of NOS. The researchers note, however, that these gains were not consistent across those NOS aspects: "Participants made relatively more gains in their understandings of the tentative, and creative and imaginative NOS, as well as the distinction between observation and inference, and the functions of and relationship 
between theories and laws. Less substantial gains were evident in the case of the subjective (theory-laden), and social and cultural NOS.” (Akerson et al., 2000, p. 312)

It is widely reported in the NOS literature that two approaches can be used for the teaching and learning of NOS (Abd-El-Khalick \& Lederman, 1998). One approach is through an implicit approach where NOS is a learning outcome that is built into other pedagogical strategies and objectives such as the teaching of scientific inquiry (e.g. Scharmann, 1990). The second approach is explicit and uses elements of history, philosophy of science (e.g. Ogunniyi, 1983) in order to support understanding of NOS. Although limited in some contexts, science teacher education programmes worldwide have been making efforts to incorporate NOS. For example, Barufaldi, Bethel, \& Lamb (1977) conducted a study in which they explored the influence of their science methods courses on elementary teachers' views of the tentative nature of science. They found that those enrolled in the treatment group classes who experienced inquiry activities held better understandings of the tentative NOS than those in the control groups. Inquiry-based approaches to science education has been used extensively to support the learning of NOS in science teacher education (e.g. Akerson \& Hanuscin, 2007; Bianchini \& Colburn, 2000).

When considering PSTs' view of NOS, it is important to visit the research literature on teachers' knowledge. In his seminal work on teachers' knowledge, Shulman (1986) categorized knowledge base for teaching as seven categories which are content knowledge, pedagogical content knowledge, curriculum knowledge, to general pedagogy, learners and their characteristics, educational contexts, and educational purposes. Content knowledge refers to "the amount and organization of knowledge per se in the mind of the teacher", including knowledge of the substantive structure and syntactic structure of the academic discipline - two terms borrowed from Joseph Schwab (1964). Also named subject-matter knowledge for teaching, content knowledge was subsequently elaborated upon by Grossman, Wilson, and Shulman (1989) as consisting of the following four components: (a) content knowledge - the "stuff" of a discipline; (b) substantive knowledge - knowledge of the explanatory framework or paradigms of a discipline; (c) syntactic knowledge - knowledge of the ways in which new knowledge is generated in a discipline; and (c) beliefs about the subject matter-feelings and orientations toward the subject matter.

Abd-El-Khalick and Akerson (2009) investigated the influence of training in metacognitive strategies on the development of prospective elementary teachers' views of NOS. These researchers observed that the participants' views were more informed after being trained in metacognitive strategies, pointing to a relationship between improved metacognitive awareness and the development of informed understandings of NOS. One potentially fruitful territory where teachers' metacognitive awareness of NOS can be supported involves visualisation. The important role of visualisation in science education has been highlighted extensively in the research literature (e.g. Gilbert et al., 2008; Dori et al., 2003). Visual representations as a tool to support cognitive understanding in science have been studied extensively (Gilbert, 2010). 
While research on pre-service teachers' views of NOS and teacher education approaches to NOS have been investigated, the role of visualisation in supporting pre-service teachers' visualisation of NOS has not been addressed. Engagement with multiple representations including visual rools is considered to be an important part of pre-service teachers' learning (Eilam \& Gilbert, 2014). Hence, a research and development project was designed to incorporate NOS from an RFN perspective in science teacher education including the incorporation of the visual tools on NOS developed by Erduran and Dagher (2014a). The study reported in the rest of the paper investigated the impact of a teacher education intervention based on RFN on pre-service science teachers' views of NOS.

\section{Methodology}

\section{Aims}

A funded research and development project was conducted in a four-year science teacher education programme at a public university in an urban setting in Turkey. The objectives of the project were to (a) produce a series of workshops in order to include RFN in science teacher education, (b) to investigate the impact of the workshops on pre-service science teachers' understanding of NOS. Table 2 summarises the main research questions, data sources and data analysis techniques used in the study.

Table 2. Research questions, data sources and data analysis techniques.

\begin{tabular}{|c|c|c|}
\hline Research questions & Data sources & $\begin{array}{l}\text { Data analysis } \\
\text { techniques }\end{array}$ \\
\hline $\begin{array}{l}\text { 1. Is there a statistically significant } \\
\text { difference in pre-service teachers' } \\
\text { views of NOS following a teacher } \\
\text { education intervention based on } \\
\text { RFN? }\end{array}$ & Questionnaires & t-test \\
\hline $\begin{array}{l}\text { 2. What is the qualitative nature of } \\
\text { pre-service teachers' views of NOS } \\
\text { based on RFN? }\end{array}$ & $\begin{array}{l}\text { Individual } \\
\text { interviews }\end{array}$ & Thematic analysis \\
\hline
\end{tabular}

\section{Research questions}

The specific research questions were as follows: 
1. Is there a statistically significant difference in pre-service teachers' views of NOS following a teacher education intervention based on RFN?

2. What is the qualitative nature of pre-service teachers' views of NOS based on RFN?

\section{Sample}

A total of 15 female pre-service science teachers participated in the study. Out of 15 preservice teachers, 4 were pre-service secondary chemistry teachers and 11 were pre-service elementary science teachers enrolled in a 4-year undergraduate teacher education programme in Turkey. The course that formed the basis of the study was offered as an elective and therefore it was open to any pre-service teachers in different programmes to enroll. All preservice teachers were senior year students at the university. They had already completed the science content based courses such as chemistry, physics, and biology, and pedagogical courses including educational psychology, curriculum, laboratory applications, and teaching methods. The teacher education sessions described in the next section culminated in the production of some lesson resources that could be used by PSTs during their teaching practice in primary schools in Turkey. However due to the limited teaching practice experiences available to PSTs (i.e. four 40-minute lessons in the span of a 14-week semester), it was not possible to trace their use of the resources given other priorities of the teacher education programme.

\section{Teacher education intervention}

The teacher education intervention included 11 3-hour sessions. Erduran and Dagher's (2014a) book was a key resource for the course. There were 2 sessions where there was a theoretical introduction to NOS and another session on RFN. For these 2 sessions, the students read reviews of literature and discussed in groups some of the key aspects of the literature. These discussions were guided by the instructor and PSTs were encouraged to think about potential applications in teaching practice of the ideas that they were encountering in the readings. Subsequently, 10 sessions were dedicated to aims and values of science, scientific practices, scientific methods, scientific knowledge and social context of science, with each category lasting 2 sessions. The first of each category was mediated by an instruction and was followed up by another session where PSTs developed lesson materials as a group. The final 2 sessions were dedicated to the design of an overall lesson resources project carried out by each group, the task being the incorporation of all the RFN categories into lesson planning for a sequence of science lessons.

In each session, a different focus on NOS was covered with a particular emphasis that was derived from the theoretical framework guiding each session. During the aims and values session, students were given a set of aims and values derived from Erduran \& Dagher's (2014a) work and were asked to draw posters to represent how they could link them to 
science lessons. In the scientific methods session, there was an emphasis on the diversity of scientific methods and PSTs debated how different methods could be utilised in various branches of science. The task on scientific methods is illustrated in Appendix A. The theme of domain-specificity (i.e. how different domains of science such as physics, chemistry and biology might have specific features that are different from each other) was incorporated in all of the sessions. The reason for this was that Erduran and Dagher (2014a) reported on a range of literature that highlighted the significance of this issue for NOS. In the workshop focusing on scientific knowledge, PSTs engaged in a task that asked them to produce examples of theories, laws, models from any domain of science. For example, for the gases topic, they wrote kinetic energy theory, gases laws and the models representing the particulate nature of gases. Each group then evaluated another group's examples to sort them out which reinforced understanding of theories, laws and models. In the second part of the activity, the pre-service science teachers researched examples of paradigm shifts where theories, laws and models would now be considered relative to how they change across time. The group then produced a poster to communicate their examples on paradigm shifts.

In the workshop focusing on scientific practices, PSTs were introduced to the Benzene Ring Heuristic (BRH) which was exemplified by the use of acid-base chemistry. Each aspect of the heuristic was reviewed and PSTs were tasked with producing examples in their groups to visually represent how they understand scientific practices. In the social context of science session, PSTs were engaged in a task where they had to produce an example topic in science (e.g. energy) and link it to the various RFN categories such as political power structures and financial systems. All sessions utilised a set of visual images that are collectively referred to as "Generative Images of Science" by Erduran \& Dagher (2014a) (Figure 2). These visual tools can potentially support meta-level understanding of NOS. The importance of metacognitive training on PSTs' understanding of NOS has been stressed in the literature (e.g. Abd-El-Khalick \& Akerson, 2009). PSTs had a copy of each of these images throughout the sessions and they were encouraged to refer to them in the context of the tasks that they were engaged in. The task focusing on the visualisation of NOS based on the images is included in Appendix A. Each session would often culminate in the production of some lesson resources in the second session. In these sessions, PSTs reviewed what they had produced the previous week and used these along with other resources like common science textbooks and the internet to produce a lesson plan focusing on the RFN category. All sessions also used numerous active learning strategies such as group discussions, presentations and posters.

\section{Data Sources}

Data are quantitative and qualitative in nature. The quantitative component is derived from the RFN questionnaire, which has been designed using the RFN categories. The qualitative data include verbal account of pre- and post-interviews with individual PSTs. The questionnaire and the interview approaches will be described in the following paragraphs in the context of the research instruments. 


\section{Research instruments}

The research instruments were questionnaires and interviews. They were administered within a week before and within a week after the teacher education intervention. The interviews were conducted first with the participants individually, and then the questionnaires were completed. The same sequence was used for both pre- and post-intervention data collection. The sequence of interview first and questionnaire second was justified on the grounds that the questionnaire items might have provided ideas to the participants that could potentially bias their interview responses. The research instruments were intended to provide both quantitative and qualitative data that could help evaluate the impact of the intervention in a mixed methods approach. Such an approach was used because given the novelty of the approach adopted in the teacher education, the aim was to make as best an assessment of the utility of this approach as possible through multiplicity of data sources. The following sections will illustrate the content and the rationale of the research instruments in more detail.

\section{RFN Questionnaire}

In order to assess pre-service teachers' views about nature of science, a 5-Likert scale instrument (RFN questionnaire) was developed (Appendix B). Even though a questionnaire may inherently be a reductive instrument in terms of capturing RFN themes in specific items, we were interested in (a) exploring the development of a new instrument because RFN is a relatively new approach in NOS, and (b) investigating whether or not there is any statistically significant impact of the RFN-based teacher education intervention that we designed. RFN is based on FRA which includes classes of ideas with infinite number of possibilities as statements based on each category. For instance, just for the "Scientific Knowledge" category, we can think of many statements related to theories, models and laws or their various relationships. As a starting point in the development of a reliable and valid instrument based on all categories of RFN, we were interested in tracing the impact of teacher education on each RFN category and the PSTs' learning outcomes specified for that category.

The RFN Questionnaire consists of 70 items which reflect the 5 RFN categories where Erduran and Dagher's (2014a) "Social-Institutional Aspects" category consisted of several sub-categories (e.g. "Political Power Structures", "Social Values", "Financial Systems") (Table 3). Given the emphasis of domain-specificity in NOS that had been placed in the teacher education sessions, some of the questions implicitly included reference to this theme. In the questionnaire, the pre-service teachers were given 5 options which are "totally agree", 'agree', "not sure", 'disagree', and "totally disagree" and they were asked to select one of these options to determine their views about each statement. The items were developed based on three criteria. The first criterion was to write items for each RFN category. For example, for the scientific practices category, we included the item "Analysis and interpretation of data are components of scientific practices." 13 statements related to scientific practices (e.g. experimentation, classification, data) were written. Similarly, 7 items were written for the 
"Aims and Values" category, 9 items for the "Methods" category, 9 items for the "Scientific Knowledge" category, 16 items for the "Social-institutional Aspects", and 16 items for the "Educational Applications" category. The second criterion was to refer to the key themes regarding each category of the RFN addressed by Erduran \& Dagher (2014). For example, one of the key ideas in the scientific knowledge category is identification of different forms of scientific knowledge (i.e. which are theories, laws, and models). Therefore, for the scientific knowledge category, the items referred to referring to theories, laws and models. were developed.

The third criterion was to develop items about educational applications of each RFN category. This is because we wanted to explore how pre-service teachers considered the teaching aspects of RFN. For example, one item was about teaching scientific aims and values in science classes and how this might affect students' cognitive ability levels. Overall, the number of items for each RFN category was determined on the basis of the instructional goals and learning outcomes intended for each session. We wanted to capture the impact on learning of those themes promoted in the sessions, such as the theme of diversity of scientific methods. As such, the number of learning outcomes were not the same for each session and hence, the number of items in the questionnaire are different for each RFN category. The questionnaire included items based on all RFN categories. Therefore, the questionnaire as a whole can be considered to be inclusive of a holistic account of NOS because RFN itself is a holistic account.

The 5-Likert scale questionnaire included both positive and negative items for each RFN category. The use of negative items in questionnaire design has been justified on the basis of reducing the acquiescence bias that occurs when people tend to agree with statements without regard for their actual content (Podsakoff, MacKenzie, Lee, \& Podsakoff, 2003). Table 3 presents example positive or negative item for different RFN categories. The number of items dedicated to each RFN category in the questionnaire is indicated. The positive and negative items for each category are referenced by the numbering system in the questionnaire. For example, for aims and values category, there are 7 items. 5 of the 7 are positive items (i.e. 2, 20, 40, 51, and 69 in the questionnaire) and 2 are negative items (i.e. 46 and 56 in the questionnaire).

In order to calculate the participants' scores from the questionnaire, first their selection of the options for each item was coded. The options of "totally agree", 'agree', "not sure", 'disagree', and "totally disagree" were coded as 5, 4, 3, 2, and 1, respectively. For the negative items, the codes of ' 5 ', ' 4 ', ' 2 ', and ' 1 ' were re-coded as ' 1 ', '2', '4', and ' 5 ', respectively. Recoding is a common approach in the interpretation of questionnaire data. In order to compute the total score for each participant based on her responses to the entire questionnaire, it is important to reverse-score the negative items so that they are all coded in the same direction. After recoding, scores for each RFN category and for the educational applications category were calculated. The total score for all RFN categories was produced and used to test statistical significance using a t-test at a significance level of 0.05. Similarly, the scores of the educational aspects of RFN were subjected to a t-test. 
For the content validity of the questionnaire, the items were checked by two experts in science education in terms of appropriateness of the items in NOS context. Based on the experts' feedback, the repetitive and unnecessary items were eliminated from the questionnaire. In order to calculate the reliability, the questionnaire was administered to 222 pre-service science teachers from two public universities. The Cronbach alpha was calculated as 0.8 .

Table 3. Positive and negative items in the RFN Questionnaire.

\begin{tabular}{|c|c|c|c|c|}
\hline \multirow[t]{2}{*}{ Category } & \multirow[t]{2}{*}{ Example } & \multirow{2}{*}{$\begin{array}{l}\text { Number of } \\
\text { items } \\
\text { dedicated to } \\
\text { RFN } \\
\text { category }\end{array}$} & \multicolumn{2}{|c|}{$\begin{array}{l}\text { Item reference in } \\
\text { questionnaire }\end{array}$} \\
\hline & & & Positive & Negative \\
\hline $\begin{array}{l}\text { Aims and } \\
\text { Values }\end{array}$ & $\begin{array}{l}\text { The diversity of scientists } \\
\text { solving a problem means } \\
\text { less biased results } \\
\text { (Positive item) }\end{array}$ & 7 & $\begin{array}{l}2,20,40 \\
51,69\end{array}$ & 46,56 \\
\hline $\begin{array}{l}\text { Scientific } \\
\text { Practices }\end{array}$ & $\begin{array}{l}\text { Each branch of science } \\
\text { has a different nature } \\
\text { (Positive item) }\end{array}$ & 13 & $\begin{array}{l}4,5,15 \\
19,23,33 \\
38,57,61 \\
63\end{array}$ & $26,52,64$ \\
\hline $\begin{array}{l}\text { Scientific } \\
\text { Methods }\end{array}$ & $\begin{array}{l}\text { All scientific disciplines } \\
\text { such as physics, biology } \\
\text { and chemistry use the } \\
\text { same scientific method } \\
\text { (Negative item) }\end{array}$ & 9 & $\begin{array}{l}11,22,24, \\
28\end{array}$ & $\begin{array}{l}8,25,37 \\
49,60\end{array}$ \\
\hline $\begin{array}{l}\text { Scientific } \\
\text { Knowledge }\end{array}$ & $\begin{array}{l}\text { Scientific knowledge does } \\
\text { not change } \\
\text { (Negative item) }\end{array}$ & 9 & $\begin{array}{l}10,30,44 \\
50,54\end{array}$ & $\begin{array}{l}3,16,43 \\
66\end{array}$ \\
\hline $\begin{array}{l}\text { Social - } \\
\text { Institutional } \\
\text { Aspects }\end{array}$ & $\begin{array}{l}\text { Scientists should respect } \\
\text { the environment } \\
\text { (Positive item) }\end{array}$ & 16 & $\begin{array}{l}7,9,14 \\
32,34,41 \\
45,48,53 \\
58,67,70\end{array}$ & $\begin{array}{l}13,18 \\
36,39\end{array}$ \\
\hline
\end{tabular}




\begin{tabular}{|l|l|l|l|l|} 
Educational & Teaching science should & 16 & $1,6,12$, & $35,47,68$ \\
applications & specify that laws are & & $17,21,27$, & \\
& certain and & & $29,31,42$, & \\
& unchangeable. & $55,59,62$, & \\
& (Negative item) & & 65 & \\
\hline
\end{tabular}

\section{Interviews}

The primary objective of the interviews was to elicit PSTs' views of RFN in more detail and to supplement the quantitative data in order to trace the impact of the teacher education intervention. Hence, questions were designed to give PSTs a chance to talk about each RFN category and its implications for educational practice. The interview includes 15 questions referring to each RFN categories (i.e. values and aims, scientific practices, scientific methods, scientific knowledge, and social-institutional aspects). In other words, for each of the 5 categories there were 3 questions. Two of these questions were about what is meant by the terms and the third was about the educational applications. The sample interview questions about aims and values are "What comes to your mind when I say scientific aims and values? Could you give examples?", "Do you think scientific aims and values are taught in science lessons? If yes, how they are taught? If no, how can scientific aims and values be taught in science lessons?" The rest of the interview protocol included similar questions for each RFN category, for example by substituting "aims and values" with "scientific practices". Each interview lasted about 20-25 minutes. Each interview was audio-recorded and transcribed. Two research assistants, co-authors of this paper transcribed the interviews. All authors of this paper contributed to the data analysis.

\section{Quantitative Results}

\section{Results and Findings}

T-test results show that there was an overall significant difference between PSTs' pre- and post- views about RFN ( $\mathrm{t}=-4,306, \mathrm{p}=.001)$ suggesting that the teacher education intervention has made a significant impact on PST's views of RFN. While there was an overall significant difference, further investigation of each category points to a variation in the way that PSTs view different RFN categories. In the case of the categories of aims and values $(t=-2,476$, $\mathrm{p}=.027)$, scientific methods $(\mathrm{t}=-5.639, \mathrm{p}=.000)$, scientific knowledge $(\mathrm{t}=-2.898, \mathrm{p}=.012)$ and social and institutional systems $(\mathrm{t}=-3.031, \mathrm{p}=.009)$ the significance was in the favour of postscores, again suggesting that the teacher education intervention has made an impact on PSTs relative to these categories. On the other, a closer look at the pre- and post-scores for the categories of scientific practices $(\mathrm{t}=1.209, \mathrm{p}=.247)$ suggests that there was no significant difference. The results regarding scientific practices can be interpreted in relation to PSTs' previous exposure to this topic. Most PSTs were aware of scientific practices as covered in the teacher education intervention. The teacher education intervention utilised the Benzene 
Ring Heuristic (BRH) from Erduran and Dagher's (2014a) visual tools which emphasised particular aspects such as modeling, explaining and predicting. The same tool had been used in a previous course in the teacher education programme that the majority (i.e. 11 of 15) of the PSTs took prior to the intervention. It is therefore not surprising that their views on scientific practices did not shift significantly. In terms of the educational applications for RFN, there was a significant difference between PSTs' pre- and post-views $(\mathrm{t}=-2.674$, $\mathrm{p}=.018$ ) suggesting that they were more inclined to view NOS as a significant educational goal.

\section{Qualitative Results}

Verbal data from individual interviews with PSTs before and after the intervention were analysed. The results of the qualitative data analysis are consistent with the findings from the quantitative analysis. In other words, the changes in PSTs' pre- and post- scores were significant for aims and values, scientific knowledge, scientific methods and socialinstitutional aspects whereas there wasn't much of a difference for the scientific practices category due to the PSTs' previous exposure to this theme in another course. Before unpacking the qualitative data from the interviews, we note that one of the main emphasis of the teacher education sessions was the issue of domain-specificity. Throughout the entire intervention, this theme was highlighted and it can be seen that it was promoted in Task 1 (Appendix A) where the PSTs were tasked to discuss whether or not different science disciplines use the same methods. At the end of the intervention, one PST reflected on her learning about scientific methods as follows:

We learnt the scientific methodology in high school as determining the problem, constructing hypotheses, collecting data, testing the hypothesis and finally reaching the conclusion. After taking this course, I learnt that scientific methodology is not like that and there are many scientific methods. Besides, I learnt each discipline can use different methods and reach the conclusion. For example, each discipline should not use experimentation or support it to prove. We can do vice versa too. So, different methods can be used for same and different subjects. For example, our last project subject was about Stars and we cannot make manipulation, we can just use observation or use historical evidence.

The theme of domain-specificity came up in reflections about scientific knowledge as well. Another PST explicitly referred to her learning about forms of scientific knowledge and how her thinking about this issue has shifted as a result of the intervention:

I suppose that each subject has its own scientific knowledge and so they are not related to each other. However, I do not think so now. Theory, law and model are three types of scientific knowledge that support to each other, enrich and lead to growth of scientific knowledge. So, theories, laws and models of each discipline which physics, chemistry and biology are actually not independent of each other. These are continuous. They 
change, improve and reconstruct. Already, this results in to reach us scientific knowledge.

The reflective element of the PSTs responses was encouraging and suggests that the emphasis on domain-specificity in the teacher education sessions influenced them. In the next sections, the results from the pre- and post-intervention individual interviews are reported for each RFN category. As noted earlier, the results of the qualitative data from interviews were consistent with the changes in PSTs' pre- and post- scores from the quantitative data. Examples of PSTs' interview data for aims and values, scientific knowledge, scientific methods and social-institutional aspects are presented to highlight the consistency in the patterns between the quantitative and qualitative data analysis. There wasn't much of a difference for the scientific practices category due to the PSTs' previous exposure to this theme in another course. This result is also consistent between the quantitative and qualitative analyses. Finally, the results about the changes in PSTs' views about the educational aspects are discussed.

\section{Aims and Values}

The interview results indicate that the differences between pre-service teachers' pre- and post-intervention views of aims and values of science was significant. In their pre-interviews, most PSTs emphasized serving humanity, understanding the universe, and ethical issues as examples of aims and values of science. For example, in her pre-interview, PST1 said:

It is going to be a cliché but [aims of science] sounds like "let's learn about the environment, the Earth". The aim of science keeping up with modern developments and technology. Other than that, it could be learning about the essential phenomena happening around us and in our lives. I cannot think of much about values of science. I am trying but really, I cannot make up anything.

As seen in this excerpt, PST1 perceived aims of science as learning about the environment and the earth, and keeping up with modern developments and technology. Additionally, she stated that she could not think about values of science. While PST1 previously had limited views about aims and values of science, she referred to epistemic, cognitive and cultural aims and values such as accuracy, honesty after the intervention. Furthermore, whereas before the intervention she could not refer to values of science, after the intervention she mentioned being free of bias and cultivating honest science as values of science. An example quotation from PST1's post-interview is given below:

Aims and values of science... It reminds me epistemic, cognitive and cultural aims and values. There are interrelated concepts. Epistemic and cognitive is more related with information, cultural is more about social aspects. Also, I think there are subcategories under them. For example, when I think of aims and values of science, I first think of 
accuracy and honesty. These concepts are central. /.../ Values of science are, firstly, being free of bias. Cultivating an honest science. It should be the most important aim and value. Other than that, it could be creating accurate knowledge. I think these are the essential ones.

Similarly, in their post-interviews the PSTs mentioned epistemic, cognitive and social aspects of science, exclusion of prejudice and bias, honesty in science, accuracy of scientific knowledge, and scientific literacy in addition to serving humanity. These concepts had been covered in the teacher education sessions. Overall, the qualitative results indicate a positive impact of the intervention on PST's views of aims and values. This result is consistent with the findings from the quantitative analysis.

\section{Scientific Methods}

For methods category, qualitative results indicate a significant difference between PSTs' preand post-views of methods. For example, PST2 referred to a step by step method in her preinterview:

First of all, defining a problem. So, that process. Defining a problem, making observations, making inferences based on observation, forming and testing hypothesis, and if there is a problem, restart the investigation. Then, if it is a theory, you've got the theory; if it is a law, you've got the law.

Although she previously mentioned only the steps of the scientific method (i.e. defining problem, forming and testing hypothesis) after the intervention, PST2 emphasized diversity of methods used in science by referring to "testable and non-testable things, forming or not forming a hypothesis" and "using or not using scientific practices". Such dichotomies that she drew after the intervention are in sharp contrast to a more simplistic account in her preintervention statements.

Methods, in general... I am thinking about testable and non-testable things, forming or not forming a hypothesis. There was a table that comes to my mind. Using or not using scientific practices, actually determining their own scientific practices. Scientists or the things that they do based on scientific aims. By forming a hypothesis or not. Also, we can reach unexpected results in contrast to our hypotheses. There might be some scientific phenomena such as evolution that we cannot directly observe. For these, we might use different data collection methods. There are different data collection methods for different branches of science such as physics, chemistry and astronomy. /.../ There are some methods based on observation or experimentation. We might make inferences based on direct observation or based on data. By observing, experimenting, when direct observation is not possible by making inferences from other observations like evolution. Making inferences based on data collected. 
The manner in which PST2 is problematising the complexity of scientific methods is noteworthy. She is not only referring to aspects of scientific methods but also highlighting the limitations of observations and inferences. She has grown aware that there may be unexpected results which demand reconsideration of hypotheses. Similar sophistication in other PSTs responses have been observed in the data. Overall, in their pre-interviews, the PSTs referred to observation, hypothesis, experimentation, and controlling variables. However, in their post-interviews they mentioned hypothesis and non-hypothesis testing, manipulation and non-manipulation, and diversity of methods in different domains of science. The interview results are consistent with questionnaire analysis since they point to an improvement of the PSTs' views of scientific methods after the intervention.

\section{Scientific Knowledge}

For the scientific knowledge category, the questionnaire and interview analyses point to consistent results in terms of improvement in favour of the post-intervention. Prior to the intervention, the PSTs mentioned tentativeness of scientific knowledge, accuracy of scientific knowledge, supported and tested knowledge in their pre-interviews. They did not refer to growth of scientific knowledge and different types scientific knowledge including models. For example, PST3 did not think about what is actually meant by scientific knowledge:

Scientific knowledge is something that at least has been verified about its truth but of course it can change. Every day, a new development arises. So, I think, scientific knowledge is supported knowledge in the current conditions. However, it can change, something can be added, it can change and something can be added. /.../ Forms of scientific knowledge...Nothing comes to my mind in terms of its kinds of scientific knowledge.

Although she had previously mentioned the process of change in scientific knowledge, after the intervention PST3 had a fairly sophisticated response about growth of scientific knowledge:

I can say that scientific knowledge has three forms: theories, models and laws. I would have thought of theories and laws but I never thought of models as forms of scientific knowledge. When I was answering the questions initially, I was like, what the heck is scientific knowledge form?! When I learned about them later, I couldn't quite place models but that too ended up firming up in my mind. Up to this point, we thought: a theory is proposed. Even if this is true, it is not something that is proven. When theories emerge through particular experiments and their truth is validated, they become laws. This was the sort of thing we learned. But we knew from our previous courses that it's not like this. Like laws are a different thing. Theories are a different thing. We learned that you don't need to prove one to have the other. But we didn't learn the rest. Here, we learned that scientific knowledge forms work together to enable growth of scientific knowledge and they contribute to knowledge development. Laws support theories. Models make them more meaningful and comprehensible. They 
progress together by supporting each other. Of course, it's not like this law supports this theory, so clear cut as that. Perhaps there will be a different observation, something will be done. A new model will be put forward. That model might destroy the theory and a new model will emerge. Or a new theory will be formed. This will be a process where they support each other and progress together.

The post-intervention themes that PSTs mentioned included some of the key ideas that were highlighted in the teacher education sessions but which were not part of their pre-intervention statements. These included growth of scientific knowledge, domain-specificity of scientific knowledge and forms of scientific knowledge as being theories, laws and models. These findings suggest that the intervention positively influenced PSTs' understanding of scientific knowledge and its growth.

\section{Social-Institutional Aspects}

For social-institutional aspects the interview results indicate that PSTS' views indicate a shift after the intervention. This result is consistent with questionnaire analysis. In their preinterview, pre-service teachers referred to themes such as communication with society, scientific literacy, social sciences, serving humanity, scientific and educational institutions. A particular observation was that the institutional aspects of science was not something that the PSTs had previously considered. Consider, for example, PST 4's pre-intervention data:

When I think of social aspects...I think they are for the aspects of science that can affect society to be open for discussions. Individuals can discuss positive and negative aspects of science on the society, or how they can contribute the society, what would be the disadvantages or advantages. For example, as an example for social aspects. For example, there are animals that are going extinct. What affects them? There is global warming. What are the factors affecting them? How they affect the society and world? These came to my mind. When you say institution, I think of buildings like school. Institutional, the institutions that work in science comes to my mind. Since never thought about institutional aspect of science, to be honest I cannot think of anything explanatory.

Following the intervention, PST4 had a much more nuanced articulation of the socialinstitutional aspects of science:

When we say social aspects of science we understand it in this way...when we were little... rather...like science is something that is done behind closed doors. Just scientists do it and they present. We just know that we only know about the results or products, but it is a process. Scientists can participate in many conferences, they share and publish their studies in journals, they are criticized by other scientists. Besides, a financial support is needed for all scientific knowledge to be generated and the government should support scientists. This is a thing that is done on a large scale, we only feel like scientists are alone, but it is not like that, science has different aspects. For example, as an example to social aspects of science, is like the one as I told before 
but... For example, I had read a news story. Let me give an example from the news I have read. A scientist is studying a virus he has made, and he is publishing the data online over the internet. By publishing them online, he makes it possible for other scientists to contribute and criticize if he has done anything wrong. Normally, scientists publish articles, it can be accepted or revised. He was published the data online in order to shorten this task and process. This social... He shares, the things he does is not kept like a secret, they are shared instantly. I believe the data he has shared was more up-to-data and reliable. About the institutional aspects of science, I think of the institutions and organizations such as universities and research centers in which science takes place. For example, the fact that we are getting educated in universities, and attending seminars and conferences is a part of institutional aspect of science.

Hence, PST4 was quite particular about how she mentioned the institutional aspects and furthermore, she referred to other related concepts such as scientists' professional activities. Overall, after the intervention, the PSTs mentioned most categories of social-institutional systems of science including political power structures, scientific ethos, social discourse and dissemination, financial systems, professional activities, and scientific institutions.

\section{Scientific Practices}

The preceding RFN category results indicate a positive improvement in PSTs' views after participating in the teacher education sessions. In the case of the scientific practices category, there was no difference in the quantitative analysis and likewise, no difference was observed qualitatively. As stated earlier, this is likely due to the fact that PSTs had previous exposure to this theme through another course. The interview results show that the difference between PSTs' pre- and post-views of scientific practices was not significant. In her pre-interview, PST5 referred to scientific activities, experiment, and model as the examples for scientific practices:

When I say scientific practices, it reminds me of some scientific activities and experiments. I mean the concrete concepts and methods. I... It could be developing some models. We can form a model for the concept that we teach. We could ask them (students) to form a model which is consistent with the model we formed.

Similarly, in her post-interview, PST5 mentioned different scientific practices including data and model:

Scientific practices... For example, observation comes to mind. I mean real world, data, model. The Benzene Ring Model comes to my mind. Scientific practices in this Benzene Ring Model are related to each other... In other words, while you are conducting a research or an experiment, you benefit from the whole ring, from everything in this model. What comes to my mind is interpretation, explanation, real world, activities, data, model. Of course, furthermore it comes to my mind that these are around the 
social, discussion and social discourse and reasoning. Yes, you are conducting a study but if you do not explain or discuss its reason, your study would not have a significance. So, the question is so what? So, it is does not make sense. Therefore, when you say scientific practices, these comes to my mind.

Even though PST5 did not explicitly refer to the BRH to explain scientific practices in her pre-interview, she could explain the components of the BRH. Furthermore, although she had a more elaborate response in the post-interview, the ideas presented are fairly similar to the pre-interview. It is likely that participating in the teacher education sessions consolidated her existing views on scientific practices but there isn't a major difference in how she is discussing scientific practices. For example, she mentions models and modeling in both interviews. Since the cohort of PSTs had previously taken a course on scientific practices, their views were not impacted to a great extent by participating in the sessions. The qualitative findings are consistent Overall, these qualitative results are consistent in this regard with quantitative findings which pointed to a lack of significant difference between PSTs' pre- and post-intervention views of scientific practices.

\section{Educational Applications}

Apart from questions about the RFN categories, the individual interviews also explored how PSTs view the educational aspects of RFN. For instance, the interview questions addressed how NOS should be taught, what the curriculum should include and how students should engage in science lessons in order to learn about NOS. The questions emphasised not only individual RFN categories and their educational implications but also the educational applications of all RFN categories collectively. In other words, PSTs were queried about their views on bringing together all categories at the end of an instructional sequence. Before the intervention when the PSTs were asked "How do you think students can benefit from bringing these various aspects of science together in science classes? So what kind of skills do students gain with this type of approach?" they had limited ideas. For example, PST2 referred to questioning and being curious to explain educational applications of RFN:

First of all, they can see what is done and why, and they can form their own explanations. For example, we as a generation were not raised like that. We were not raised to be curious. Because of the fact that we do not question, we were not curious about something and we accepted something very quickly. But we can raise a curious generation who is more involved in science by questioning. Hence, I think we can get a generation who are more related to science, know at least what science is and contribute to their environment, and even if that's not the case they would be at least more knowledgeable and more sceptical.

While PSTs previously had limited ideas about educational applications, after the intervention they were more verbal about specific pedagogical approaches such as the use of technology and discussions in science lessons. They referred to the FRA wheel (Figure 1) as a tool used in teacher education sessions to explain their ideas about educational applications. 
For example, although PST2's pre-intervention views only included themes like questioning and curiosity, her post-intervention interview indicated more comprehensive set of ideas. When she was asked "Do you think it is possible that different aspects of science are brought together in science education?" she said:

I think it is possible. We have seen that it is possible during the course. This can be done so that they can understand science better. Isn't it our aim anyway? It is more integrating science into science lessons. The aim is to construct scientific literacy in children. Here, the aim is raising scientifically literate people. How to do it is by showing aims and values of science, scientific knowledge, and methods and methodologies. There was a wheel after doing all these. Maybe, it can be done by using $3 D$ models, specifically by using visuals, analogies like the wheel in our course. It is better when students explore by themselves because probably you also were raised through this kind of education. The knowledge was given to us directly and we could not explore anything. When we explore it, the information becomes more valuable for us. Maybe we can help students explore the content of nature of science. That way, we can create a more clear and permanent perception. Of course, 3D models would help a lot.

Similarly, there was a marked difference in how other PSTs discussed the educational applications of RFN. For example, in the pre-intervention interview when PST1 was asked about teaching the social-institutional aspects of science in science courses, she indicated that she was not familiar with this concept by saying "Because of I do not know well the institutionalization of science, I cannot produce something". Her discussion about the educational applications did include reference to some tools that could be used in teaching and learning:

For example, technological tools come to my mind for the institutionalization of science. Maybe, the production of technological tools... I am continuing my example, if I understand institutionalization correctly. If the production of technological tools could be institutionalized, the process of production could be explored with school trips, or students could produce something in laboratories as an activity. However, I am not sure.

In contrast, after the intervention PST1 alludes to peer assessment and group discussions as potential educational strategies for teaching the social-institutional aspects of science. She specifically refers to teaching professional activities, publishing, review process, ethical and social issues through group or individual activities in science lessons. These references suggest that PST1's views related to the teaching of social-institutional aspects of science improved after the intervention.

We can teach the nature of science by making students to create something scientific by acting like scientists. I will go on to explain by an activity. Group or individual activities could be conducted. For example, each student could invent something. Or the 
activity can be related to an issue. For example, if it is provided that each group or student is evaluated by each other, professional activities can be presented to the students. They would publish something, review each other, and at the end one work could be chosen. They could discuss what it requires for it to be published. Such activities could be done also for social values and ethos. They could also discuss a relevant current issue that has ethical or social dilemma. If it can be done in a way that students can discuss as a group and evaluate situations from social aspects, it can go beyond talking about scientific knowledge. At the end, the relation between what the students have done and science could be revealed.

In summary, the findings from the qualitative data analysis point to improvement in PSTs' views of aims and values, scientific methods, scientific knowledge and social-institutional aspects of science. Furthermore, their views on the educational applications of RFN categories also indicate a marked difference in favour of the post-intervention. These findings are consistent with the findings from the quantitative analysis. These findings coupled with the qualitative data on the outcomes of the teacher education intervention relative to the learning goals (e.g. domain-specificity theme across all sessions), suggest that the intervention has a positive impact on PSTs' views of NOS.

\section{Conclusions}

The study reported in the paper aimed to examine the effect of a teacher education intervention on PSTs' views of NOS. As such, it capitalised on the practical and empirical implications of the Family Resemblance Approach to NOS. The teacher education sessions incorporated various components of RFN such as aims and values of science and scientific practices. The impact of the intervention was investigated through the RFN questionnaire and individual pre- and post-intervention interviews. The content of the RFN questionnaire was determined by specific learning goals set for the teacher education sessions. For instance, the theme of diversity of scientific methods and domain-specificity of scientific knowledge were promoted in the sessions and were included in the questionnaire items. Likewise, the interviews explored particular issues that the teacher education had targeted for PSTs' learning.

The results suggest that the teacher education intervention had a significant impact on PSTs' views of NOS. The quantitative analysis findings indicate that teacher education intervention had an overall statistically significant difference in PSTs' views of NOS after the intervention. When the effect the intervention was investigated with respect to each RFN category, the results showed that PSTs' views of aims and values of science, methods, scientific knowledge and social and institutional systems of science improved after the 
intervention while there was no significant difference between their pre- and post- views of scientific practices. The activities covered in teacher education had very particular and focused objectives in unpacking features of RFN categories. For example, in the session for aims and values of science, the PSTs were introduced to epistemic, cognitive and social aims and values of science. They discussed the related concepts including accuracy, objectivity, and honesty. Regarding the category of scientific methods, they discussed diversity of methods used in different fields of science. In the social and institutional systems of science session, the PSTs focused on different concepts including financial systems, political power structures, and social ethos. Hence, outcomes observed are consistent with the intended objectives of the research and development project. The qualitative analysis results supported the quantitative results with respect to the findings from the overall questionnaire, and each RFN category in the questionnaire except for the category of scientific practices, which the PSTs had previously been exposed to through other courses.

The sample size of 15 PSTs can be considered to be fairly small for the quantitative methodology employed in the study. Although a t-test can be used with small sample sizes (e.g. deWinter, 2013), further analysis on effect size and power are needed to establish a reduced risk in error. In this study, the quantitative analysis was complemented with qualitative analysis which illustrated consistency in the impact of the teacher education intervention. The intention in this study was not to do an exhaustive statistical analysis on PSTs' views but rather to have some combined measure of impact of the teacher education intervention through a mixed methods approach. Considering the novelty of the RFN-based approach to NOS in science teacher education, the findings can be considered as preliminary investigations into how this approach influences PSTs' views of NOS. Future studies can be conducted with larger cohorts of PSTs to further test the power of the quantitative analyses.

Some of the findings are consistent with existing literature on NOS while others are inconsistent. For example, we noted significant difference in the scientific knowledge category through both quantitative and qualitative measures. After the intervention, most PSTs could classify scientific knowledge through the "theory, law, and model" framework and also explain processes of scientific knowledge growth. Likewise, Akerson et al.'s (2000) study observed gains in PSTs' views of scientific knowledge, in particular the functions of and relationship between theories and laws after their intervention. One point of inconsistency in the findings relates to the social-institutional aspects of science. Although we found a significant difference about the social-institutional aspects of science in PSTs' views in both through quantitative and qualitative analysis, Akerson et al. (2000) indicated that they found fewer substantial gains in PSTs' views with respect to social and cultural NOS.

Overall, the findings suggest that the teacher education intervention facilitated PSTs in relating different dimensions of science to each other. The paper contributes to understanding of how NOS can be incorporated in science teacher education and sets out a new research agenda in science education. Although the philosophical analyses of FRA have been presented in the literature, its empirical implementation in science education has been limited. 
In this respect, the paper provides empirical evidence on how the theory of FRA can be transformed to science teacher education practice through the implementation of the RFN categories. Further transformations of FRA for practical use and the improvement of emerging strategies and tools are likely to contribute to research and development on NOS in science education.

\section{Acknowledgment}

To be specified.

\section{References}

Abd-El-Khalick, F., \& Akerson, V. L. (2009). The influence of meta-cognitive training on preservice elementary teachers' conceptions of nature of science, International Journal of Science Education, 31(16), 2161-2184.

Abd-El-Khalick, F., \& Lederman, N. G. (2000). Improving science teachers' conceptions of nature of science: A critical review of the literature. International Journal of Science Education, 22(7), 665-701.

Akerson, V. L., Abd-El-Khalick, F., \& Lederman, N. G. (2000). Influence of a reflective, explicit activity-based approach on elementary teachers' conceptions of nature of science. Journal of Research in Science Teaching, 37(4), 295-317.

Akerson, V. L., Cullen, T.A., Hanson, D. L. (2009). Fostering a community of practice through a professional development program to improve elementary teachers views of nature of science and teaching practice. Journal of Research in Science Teaching, 46, 1090-1113.

Akerson, V. L. \& Hanuscin, D. L. (2007). Teaching nature of science through inquiry: The results of a three-year professional development program. Journal of Research in Science Teaching, 44, 653-680.

Allchin, D. (2011). Evaluating knowledge of the nature of (whole) science. Science Education, 95(3), 518-542.

BouJaoude, S., Dagher, Z. R., \& Refai, S. (2017). The portrayal of nature of science in Lebanese 9th grade science textbooks. In C. V. McDonald \& F. Abd-El-Khalick (Eds.). Representations of Nature of Science in School Science Textbooks: A Global Perspective (pp. 79-97). New York: Routledge.

Barufaldi, J. P., Bethel, L. J., \& Lamb, W. G. (1977). The effect of a science methods course on the philosophical view of science among elementary education majors. Journal of Research in Science Teaching, 14, 289-294. 
Bianchini, J. A. \& Colburn, A. (2000). Teaching the nature of science through inquiry to prospective elementary teachers: A tale of two researchers. Journal of Research in Science Teaching, 37, 177-209.

Chang, Y., Chang, C., \& Tseng, Y. (2010). Trends of science education research: An automatic content analysis. Journal of Science Education and Technology, 19, 315-332.

Conant, J. (1961). Science and common sense, Yale University Press: New Haven.

Cullinane, A. (2018). Incorporating Nature of Science into Initial Science Teacher Education. Unpublished PhD dissertation. University of Limerick, Ireland.

Dagher, Z., \& Erduran, S. (2017). Abandoning patchwork approaches to nature of science in science education. Canadian Journal of Science, Mathematics and Technology Education, 17(1), 46-52.

De Winter, J. C. F. (2013). Using the student's t-test with extremely small sample sizes. Practical Assessment, Research and Evaluation, 18(10).1-12.

Dori, YJ, Tal, RT, \& Tsaushu, M. (2003). Teaching biotechnology through case studies - can we improve higher order thinking skills of nonscience majors? Science Education, 87(6), 767-793. doi:10.1002/sce.10081.

Driver, R., Leach, J., Millar, R., \& Scott, P. (1996). Young people's images of science. Buckingham, UK: Open University Press.

Duschl, R. A., \& Grandy, R. (2012). Two views about explicitly teaching nature of science. Science \& Education, 22(9), 2109-2139.

Eilam, B., \& Gilbert, J. K. (2014). The significance of visual representations in the teaching of science. In B. Eilam \& J. K. Gilbert (Eds.), Science teachers' use of visual representations (pp. 3-28). Dordrecht, The Netherlands: Springer International Publishing.

Erduran, S. (2014). A holistic approach to the atom. Educacio Quimica EduQ, 19, 39-42. ISSN 2013-1755.

Erduran, S. (2017). Visualising the nature of science: beyond textual pieces to holistic Images in science education. In, K. Hahl, K. Juuti, J. Lampiselkä, J. Lavonen, \& A. Uitto (Eds.), 
Cognitive and Affective Aspects in Science Education Research: Selected Papers from the ESERA 2015 Conference, pp.15-30, Dordrecht: Springer.

Erduran, S., \& Dagher, Z. (2014a). Reconceptualizing the nature of science for science education: Scientific knowledge, practices and other family categories. Dordrecht: Springer.

Erduran, S., \& Dagher, Z. (2014b). Regaining focus in Irish junior cycle science: Potential new directions for curriculum development on nature of science. Irish Educational Studies, 33(4), 335-350.

Erduran, S., Kaya, E., \& Dagher, Z. R. (2018). From lists in pieces to coherent wholes: Nature of Science, scientific practices, and science teacher education. In J. Yeo, T. W. Teo, \& K. S. Tang (Eds.). Science Education Research and Practice in Asia-Pacific and Beyond (pp. 3-24). Singapore: Springer.

Ford, M. (2008). 'Grasp of practice' as a reasoning resource for inquiry and nature of science understanding. Science \& Education, 17, 147-177.

Gilbert, JK. (2010). The role of visual representations in the learning and teaching of science: an introduction (pp. 1-19).

Gilbert, J., Reiner, M. \& Nakhleh, M. (2008). Visualization: theory and practice in science education. Dordrecht, The Netherlands: Springer.

Grandy, R. \& Duschl, R. A.(2007). Reconsidering the character and role of inquiry in school science: Analysis of a conference, Science \& Education, 16(2), 141-166.

Grossman, P. L., Wilson, S. M., \& Shulman, L. S. (1989). Teachers of substance: subject matter knowledge for teaching. In M. C. Reynolds (ed.), Knowledge Base for the Beginning Teacher, pp. 23-36. New York: Pergamon.

Irzik, G., \& Nola, R. (2011). A family resemblance approach to the nature of science for science education. Science \& Education, 20, 591-607.

Irzik, G. \& Nola, R. (2014). New directions for nature of science research. In M. Matthews, International Handbook of Research in History, Philosophy and Science Teaching. pp. 9991021. Springer.

Kaya, E. \& Erduran, S. (2016). From FRA to RFN, or how the Family Resemblance Approach can be transformed for science curriculum analysis on nature of science. Science \& Education, 25(9), 1115-1133. 
Kaya, E., Erduran, S., Akgun, S., \& Aksoz, B. (2017). Öğretmen Eğitiminde Bilimin Doğası: Bütünsel Bir Yaklaşım. Necatibey Faculty of Education Electronic Journal of Science and Mathematics Education, Vol. 11, Issue 2, December 2017, pp. 464-501.

Kimball, M. (1968). Understanding the nature of science: A comparison of scientists and science teachers. Journal of Science Teaching, 5, 110-120.

Kampourakis, K. (2016). The "general aspects" conceptualization as a pragmatic and effective means to introducing students to nature of science. Journal of Research in Science teaching, 53(5), 667-682.

Lederman, N. G. (1992). Students' and teachers' conceptions of the nature of science. A review of the research. Journal of Research in Science Teaching, 29(4), 331-359.

Lederman, N. G., Abd-El-Khalick, F., Bell, R. L., \& Schwartz, R. S. (2002). Views of nature of science questionnaire (VNOS): Toward valid and meaningful assessment of learners conceptions of nature of science. Journal of Research in Science Teaching, 39(6), 497-521.

Lederman, N. G., \& Zeidler, D. L. (1987). Science teachers conceptions of the nature of science: Do they really influence teaching behavior. Science Education, 71,721-734.

Matthews, M. (2012). Changing the focus: From nature of science (NOS) to features of science (FOS). In M. S. Khine (Ed.), Advances in nature of science research (pp. 3-26). Dordrecht, The Netherlands: Springer.

McComas, W. (2002). Nature of science in science education: rationales and strategies. New York: Kluwer.

McComas, W. F. \& Olson, J.K. (1998). The Nature of Science in International Science Education Standards Documents. In McComas (Ed.) The Nature of Science in Science Education: Rationales and Strategies (pp. 41-52). The Netherlands: Kluwer Academic Publishers.

McDonald, C. V. (2017). Exploring representations of nature of science in Australian junior secondary school science textbooks: A case study of genetics. In C. V. McDonald \& F. AbdEl-Khalick (Eds.). Representations of Nature of Science in School Science Textbooks: A Global Perspective (pp. 98-117). New York: Routledge.

McDonald, C. V. (2010). The influence of explicit nature of science and argumentation instruction on preservice primary teachers' views of nature of science. Journal of Research in Science Teaching, 47(9), 1137-1164. 
Ogunniyi, M. B. (1983). Relative effects of a history/philosophy of science course on student teachers' performance on two models of science. Research in Science \& Technological Education, 1,193-199.

Podsakoff, P.M., MacKenzie, S.B., Lee, J.Y., \& Podsakoff, N. P. (2003). Common method biases in behavioral research: A critical review of the literature and recommended remedies. Journal of Applied Psychology, 88(5), 879-903.

Rubba, P., \& Anderson, H. (1978). Development of an instrument to assess secondary students' understanding of the nature of scientific knowledge. Science Education, 62(4), 449458.

Sandoval, W. A. (2005). Understanding students' practical epistemologies and their influence on learning through inquiry. Science Education, 89(4), 634-656.

Scharmann, L.C. (1990). Enhancing the understanding of the premises of evolutionary theory: The influence of diversified instructional strategy. School Science and Mathematics, 90, 91-100.

Schwab, J. (1964). Structure of the disciplines: Meanings and significances. In G. Ford \& L. Pugno (Eds.), The structure of knowledge and the curriculum (p. 6-24). Chicago: Rand McNally.

Schwartz, R. S., Lederman, N. G., \& Crawford, B. A. (2004). Developing views of nature of science in an authentic context: An explicit approach to bridging the gap between nature of science and scientific inquiry. Science Education, 88, 610-645.

Yacoubian, H. A., \& BouJaoude, S. (2010). The effect of reflective discussions following inquiry-based laboratory activities on students' views of nature of science. Journal of Research in Science Teaching, 47(10), 1229-1252. 


\section{Appendix A}

\section{Example tasks used in teacher education sessions}

"Scientific methods" task

Claim 1: All science disciplines use the same methods. There is one universal scientific method.

Claim 2: All science disciplines do not use the same methods. Each discipline uses a different method.

- In your groups, each person will chose either claim 1 or 2 and produce a list of reasons to support this claim. (You may or may not agree with the claim. Focus on producing the reasons, not agreeing or disagreeing with the claim.)

- You will then argue your position with the opposite point of view. You can use pages 92-104 from Erduran and Dagher's (2014a) book to produce the reasons to support your claims.

- After discussing your claims in your groups, produce a poster to summarize the key ideas for each claim. 
"Visualising nature of science" task

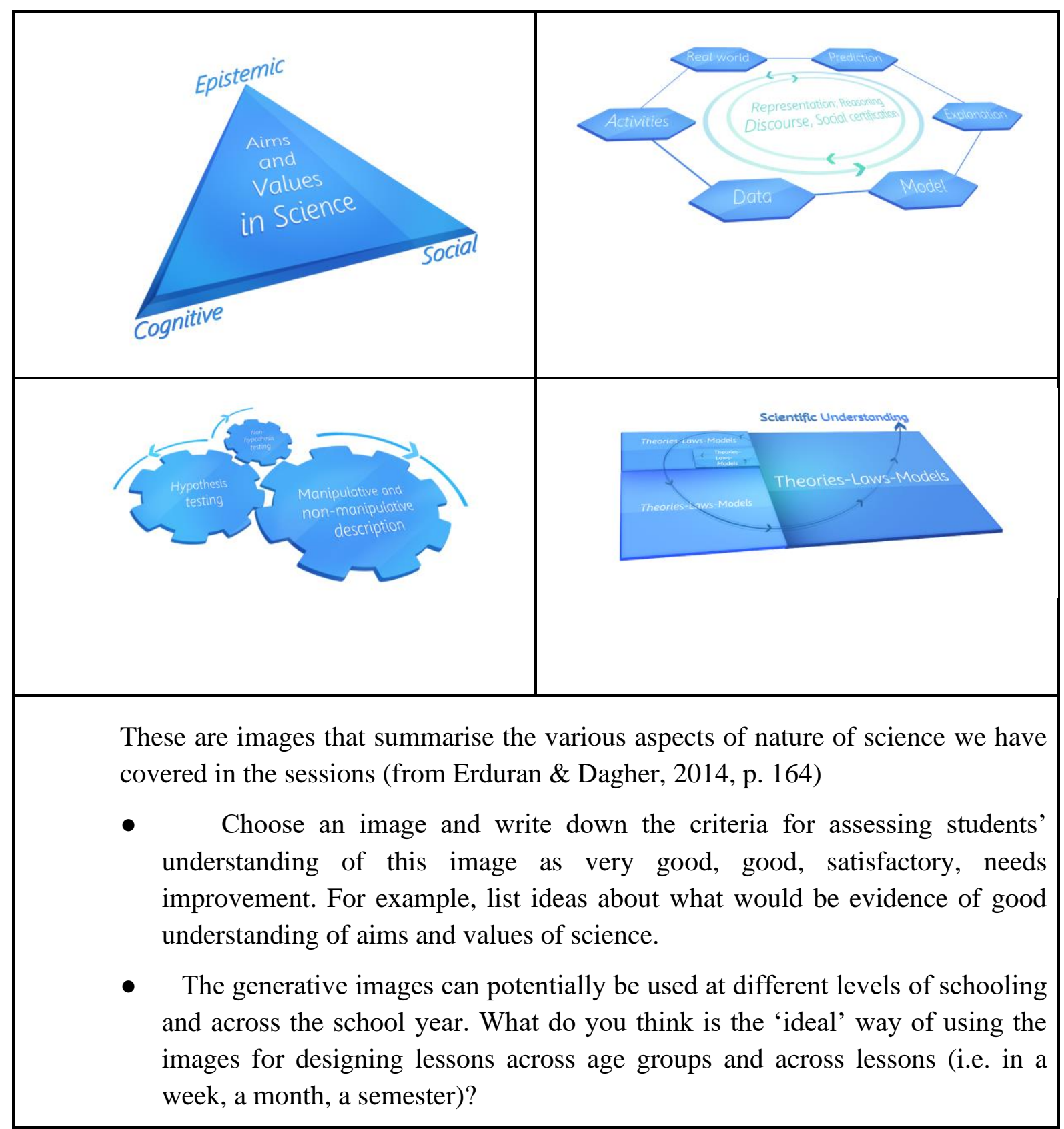


Appendix B: RFN Questionnaire

\begin{tabular}{|c|c|c|c|c|c|}
\hline & $\begin{array}{l}\text { Totally } \\
\text { Disagree }\end{array}$ & Disagree & Not Sure & Agree & $\begin{array}{l}\text { Totally } \\
\text { Agree }\end{array}$ \\
\hline $\begin{array}{l}\text { 1. Science lessons should } \\
\text { include financial } \\
\text { (economical) aspects of } \\
\text { science. }\end{array}$ & & & & & \\
\hline $\begin{array}{l}\text { 2. Epistemic, cognitive and } \\
\text { cultural values of science } \\
\text { cannot be distinctly } \\
\text { distinguished from each } \\
\text { other. }\end{array}$ & & & & & \\
\hline $\begin{array}{l}\text { 3. Scientific knowledge does } \\
\text { not change. }\end{array}$ & & & & & \\
\hline $\begin{array}{l}\text { 4. Scientists review and assess } \\
\text { each other's work. }\end{array}$ & & & & & \\
\hline $\begin{array}{l}\text { 5. The power of } \\
\text { experimentation comes from } \\
\text { testing a scientific hypothesis } \\
\text { many times by scientists. }\end{array}$ & & & & & \\
\hline $\begin{array}{l}\text { 6. Concept maps can be an } \\
\text { effective way of teaching } \\
\text { classification as scientific } \\
\text { practice. }\end{array}$ & & & & & \\
\hline $\begin{array}{l}\text { 7. Science takes place in } \\
\text { institutions such as } \\
\text { universities and research } \\
\text { centres. }\end{array}$ & & & & & \\
\hline $\begin{array}{l}\text { 8. All scientific disciplines such } \\
\text { as physics, biology and } \\
\text { chemistry use the same }\end{array}$ & & & & & \\
\hline
\end{tabular}




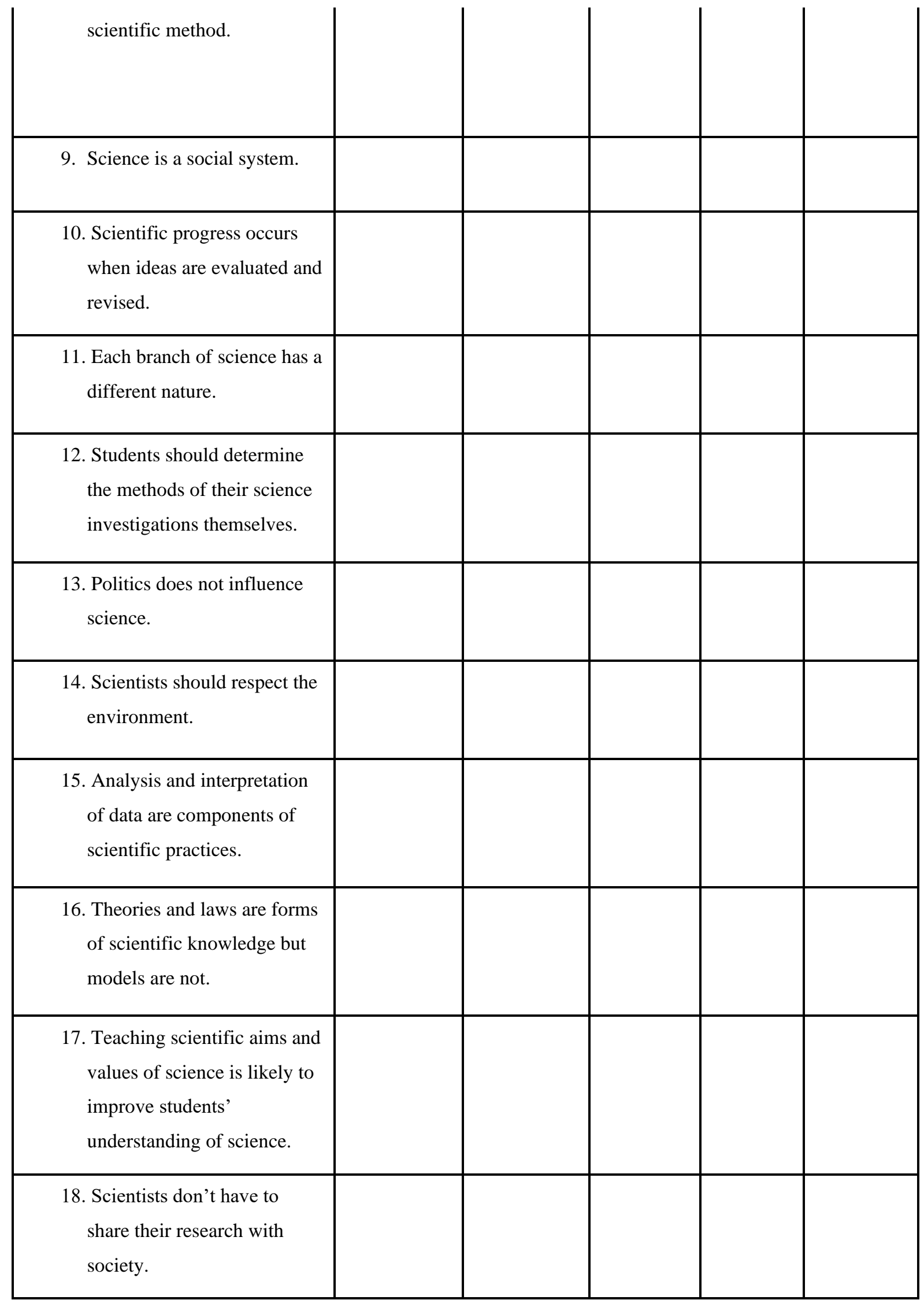




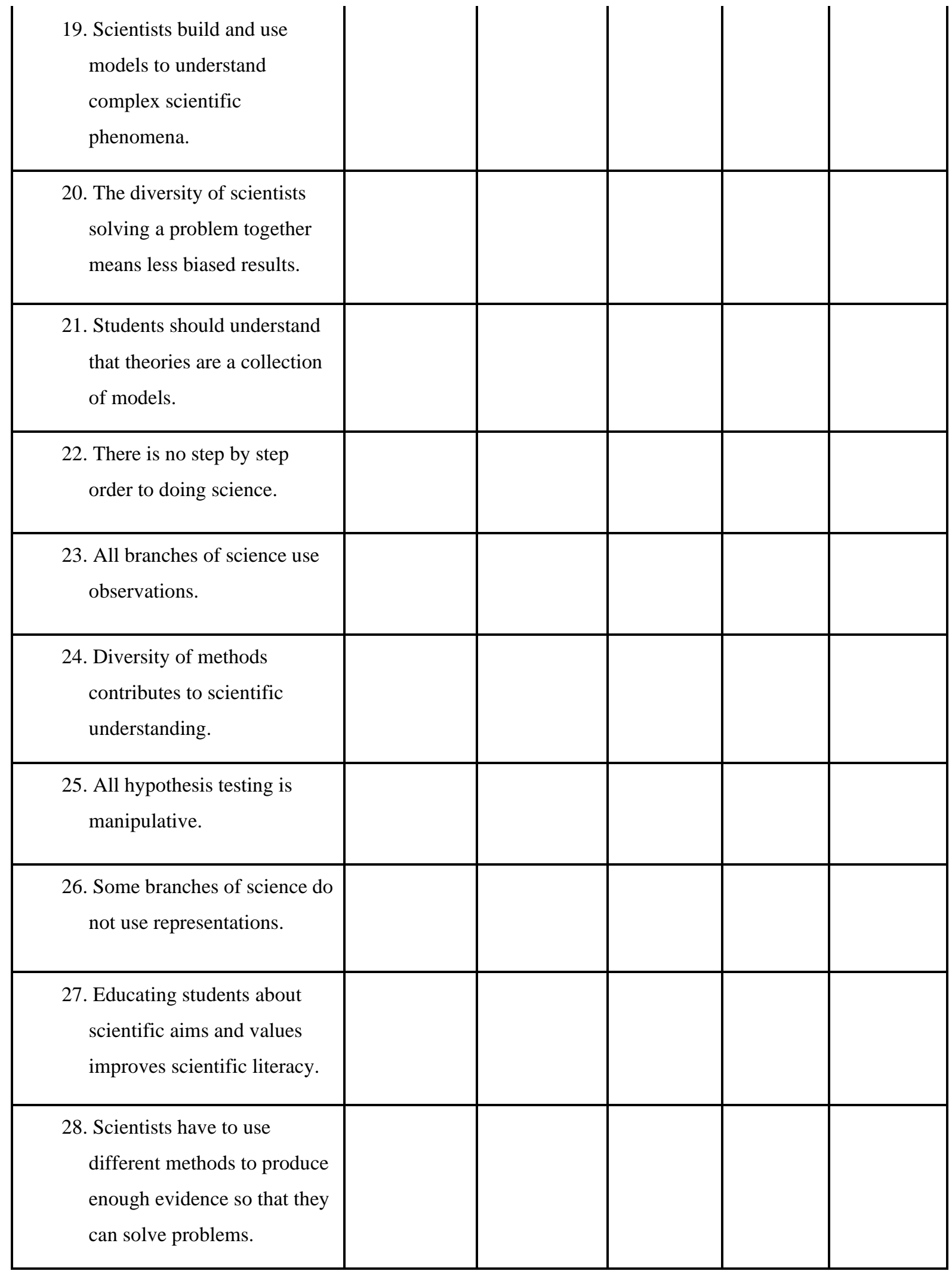


29. Students should be encouraged to collaborate with their peers in science lessons because scientists collaborate with other scientists when doing research.

30. Scientific knowledge consists of a coherent set of ideas.

31. The curriculum should stress that theories in chemistry and physics are the same.

32. Scientists need money to do research.

33. Classification helps scientists explain and predict phenomena.

34. All scientific disciplines such as physics, biology and chemistry produce values that can contribute to society.

35. It does not make a difference to students' learning of science when they participate in discussions about experimental data.

36. The gender of scientists influences how they do science.

37. There is a universal scientific method that all scientists use all over the world. 


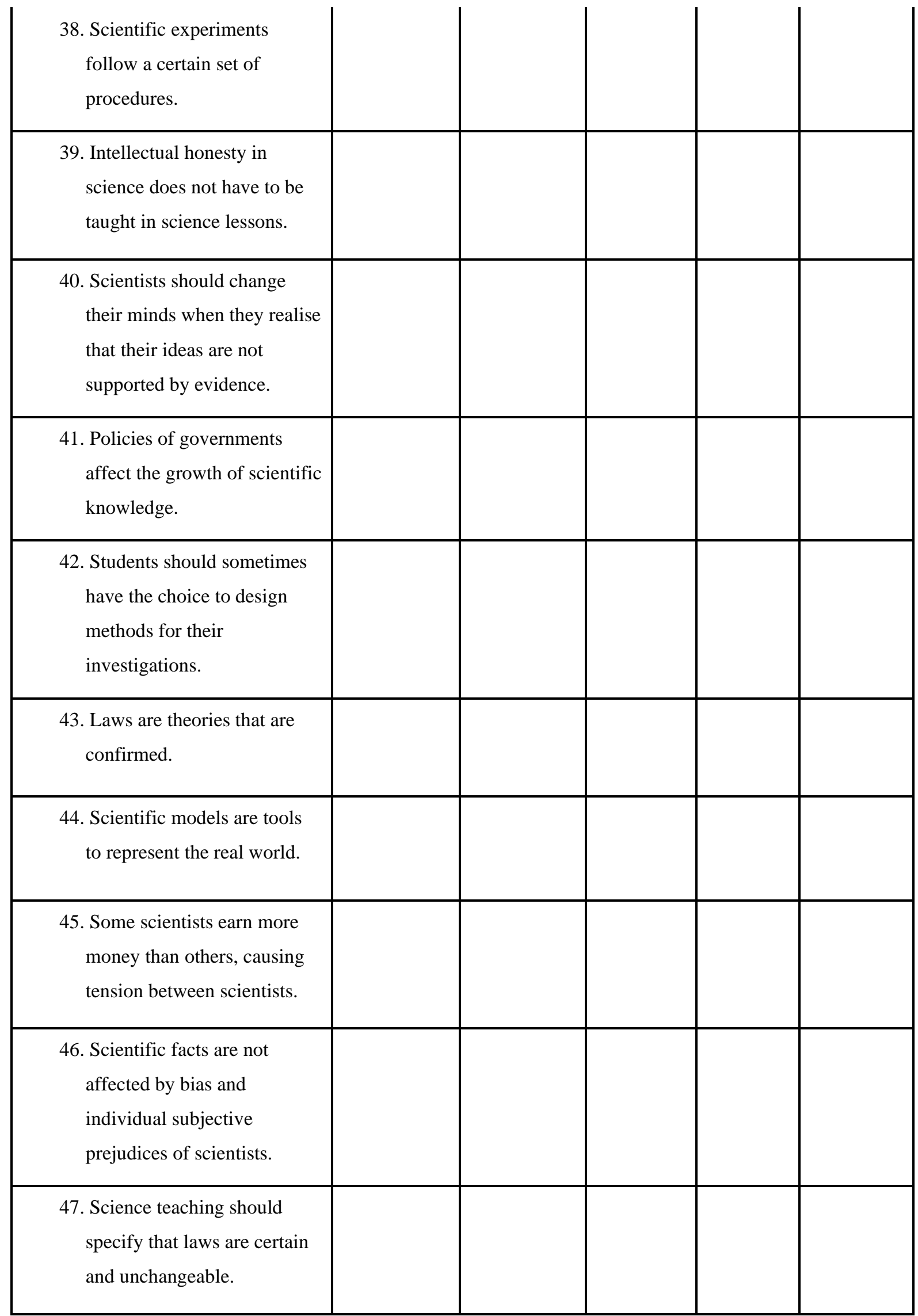




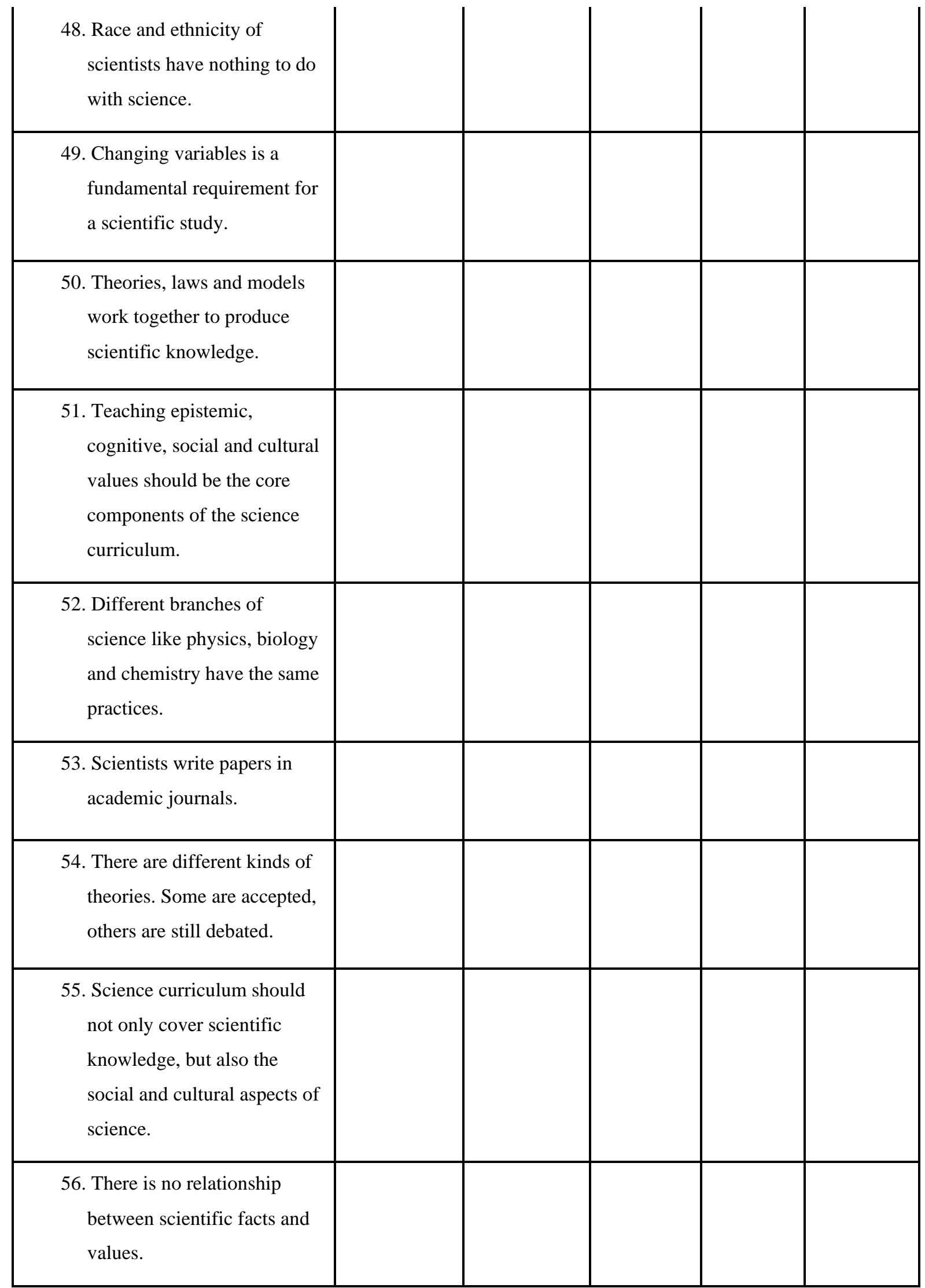




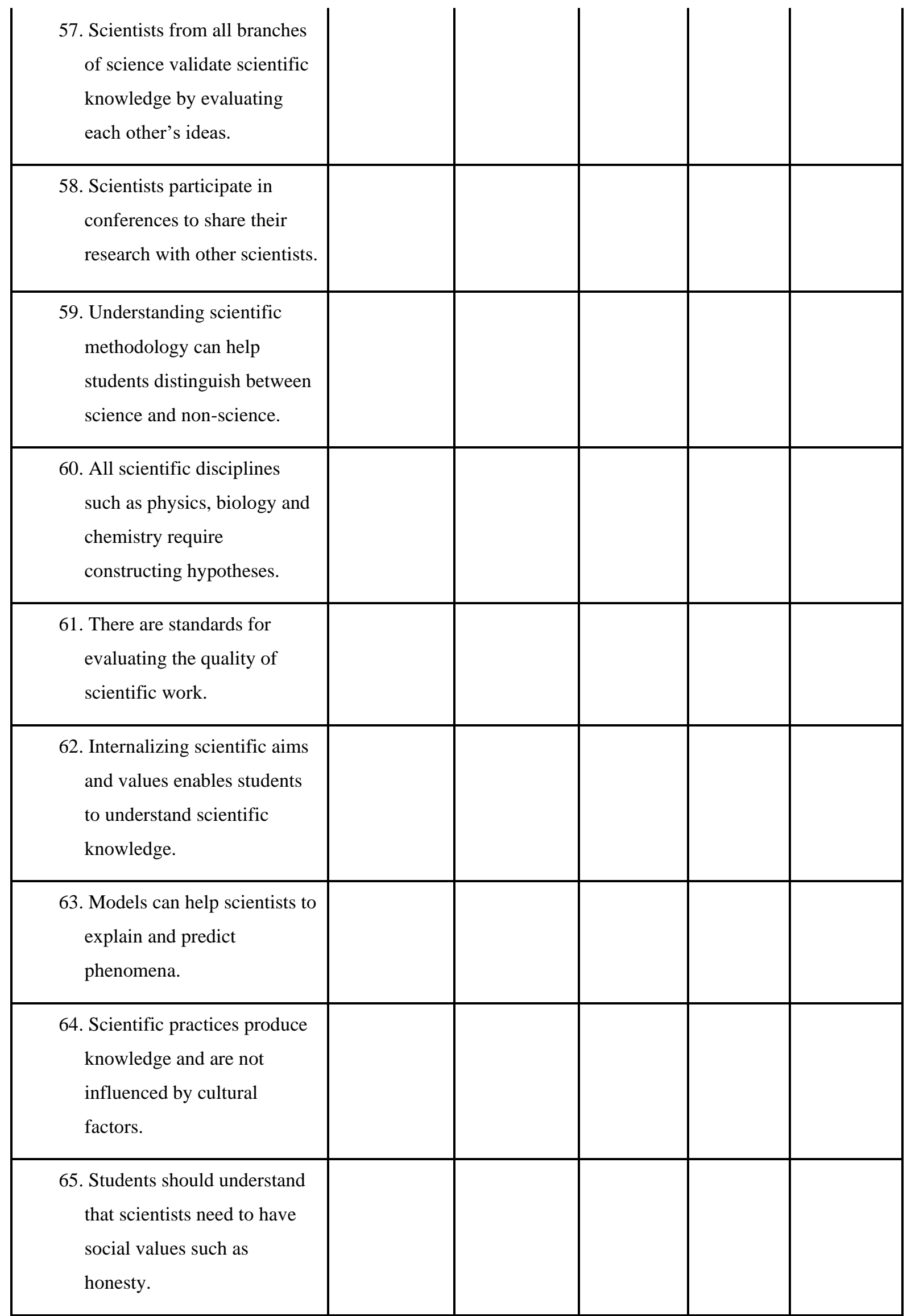




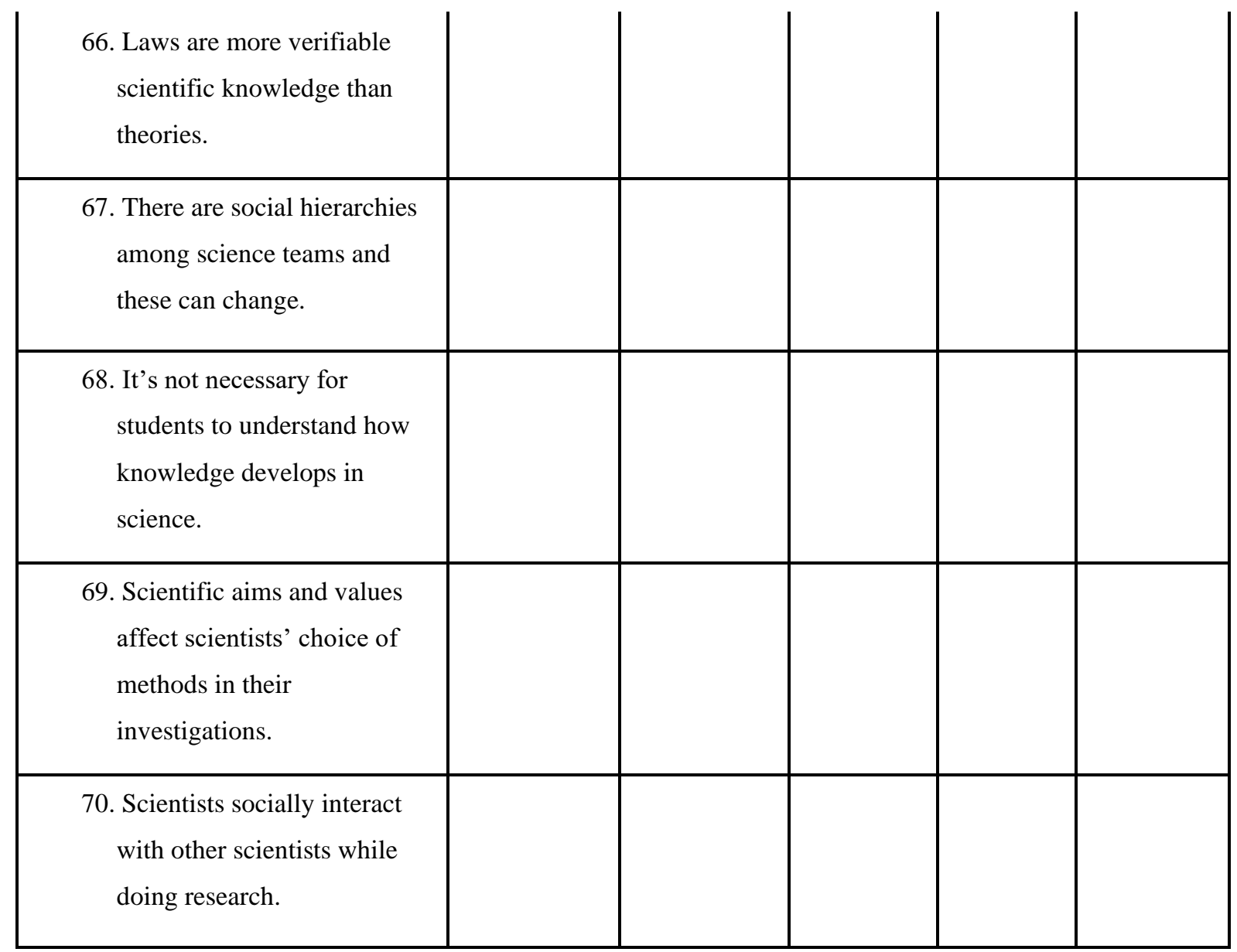

